Original Article

\title{
QBD-BASED DEVELOPMENT AND EVALUATION OF ENTERIC COATED MUCOADHESIVE MICROCAPSULES OF AMOXICILLIN TRIHYDRATE AS A NOVEL CHRONOTHERAPEUTIC APPROACH FOR TREATMENT OF BACTERIAL INFECTIONS
}

\author{
SHYAM NARAYAN PRASAD ${ }^{1}{ }^{*}$, HEMANT KUMAR PATEL ${ }^{2}$, ABHIJIT V. GOTHOSKAR ${ }^{1}$
}

${ }^{1}$ Department of Pharmacy, Shri Venkateswara University, Gajraula, Dist. Amroha, U. P., India, ${ }^{2}$ Product Development Research, Jubilant Generics Limited, Noida, U. P., India

Email: shyamnarayanpharma@gmail.com

Received: 02 Jun 2018 Revised and Accepted: 12 Jul 2018

\begin{abstract}
Objective: The present work entails design and characterization of enteric coated mucoadhesive microcapsules loaded with amoxicillin trihydrate as a novel chronotherapeutic approach for the treatment and management of bacterial infection.

Methods: The microcapsules were prepared by solvent evaporation technique using ethyl cellulose (EC) and hydroxypropyl methylcellulose (HPMC) as rate-controlling and mucoadhesive polymers, followed by a triple coating with Eudragit L100 as enteric coating polymer. Box-Behnken statistical design (BBD) was applied for optimization of formulations containing EC, HPMCK100M and Eudragit L100 as factors for selected responses like entrapment efficiency, mucoadhesive property and drug release in $24 \mathrm{~h}$. The optimized microcapsules were also characterized for particle size, drug content, swelling index, mucoadhesive strength, and in vivo antiulcer activity.

Results: The optimized microcapsules exhibited good entrapment efficiency, particle size and mucoadhesive property. FT-IR studies revealed that there was no drug-polymer interaction. SEM studies revealed that microcapsules were non-aggregated, spherical in shape and smooth appearance. In vitro, drug release data from microcapsules was fitted to different kinetic models to explain release profiles. The correlation coefficient $\left(\mathrm{r}^{2}\right)$ value indicated that drug release followed Higuchi model. Analysis of variance (ANOVA) showed a significant difference in the release of drug from all the prepared formulations at $P<0.05$ level. Accelerated stability study of optimized formulation (F4) up to 6 mo showed there was no change in drug content and release characteristics during storage.
\end{abstract}

Conclusion: Overall, the present study indicated the successful development of mucoadhesive microcapsule.

Keywords: Gastric resistance, Mucoadhesion, Swelling index, In vitro drug release, Antibacterial activity

(C) 2018 The Authors. Published by Innovare Academic Sciences Pvt Ltd. This is an open access article under the CC BY license (http://creativecommons.org/licenses/by/4.0/) DOI: http://dx.doi.org/10.22159/ijpps.2018v10i8.27699

\section{INTRODUCTION}

Amoxicillin trihydrate (AMT) is a semi-synthetic broad-spectrum $\beta$ lactam antibiotic used for the treatment of bacterial infections. It is primarily active against gram positive bacteria by inhibiting their cell wall synthesis $[1,2]$. It exhibits lower stability in gastric acid due to cleavage of $\mathrm{C} \equiv \mathrm{N}$ bond of the $\beta$-lactam ring which leads to loss of potency with reduced oral bioavailability [3]. Further, low half-life $(<1 \mathrm{~h})$ with relatively high oral dosage regimen $(250-300 \mathrm{mg}$ b. i. d/t. i. d) requires the development of a novel once-a-day oral chronomodulated drug delivery systems of AMT for the management of bacterial infections $[4,5]$.

Myriad formulation approaches have been tried viz. enteric coated tablets, sustained release mucoadhesive tablets, drug-coated beads and gastroretentive systems to protect the gastric degradation along with controlled drug absorption have limited fruition. Of late, polymeric microparticles appear to be the interesting device for their chronomodulated drug release mechanism satisfying the need of disease treatment [6]. Despite the more complex and onerous production of the multiple-unit systems, they have several advantages as compared to the single-unit products, including ready and uniform distribution in the gastrointestinal tract, minimizing the risk of local damage irritation caused by dose dumping. Furthermore, microparticles are less affected by $\mathrm{pH}$ change, gastric transit time, attain more constant plasma levels, give higher accuracy in reproducibility by dose and provide desired controlled release profile of drug delivery [7].

As these mucoadhesive drug delivery systems contains a diverse class of polymers and other inactive ingredients which may invariably affect the desired performance of dosage form. In such case, rational use of Design of Experiment (DoE) helps a lot in optimizing drug delivery systems to obtain robust formulations. Several DoE methodologies are used for optimization such as factorial design (FD), Box-Behnken design (BBD), Central-composite design (CCD), D-optimal design (DOD), Plackett-Burman design (PBD) and mixture design [8]. Of late, BBD is most widely accepted for optimization and formulation development of microspheres as the design execution and interpretation is easier over other designs. It allows the utilization of three or more components followed by optimization to obtain robust formulations with desired performance characteristics [9-11].

Therefore, the current research work entails design and characterization enteric coated controlled release mucoadhesive microcapsules of amoxicillin trihydrate as a novel chronotherapeutic system using optimized polymer blend containing ethyl-cellulose along with mucoadhesive polymers like HPMCK4M, HPMCK15M, and HPMCK100M, sodium CMC, HEC and HPC. The mucoadhesive microcapsules were prepared by a solvent evaporation method and enteric coated by dip coating technique. The microcapsules showed complete protection of amoxicillin trihydrate in the gastric acidic environment to enhance the systemic availability of the drug with desired sustained release action and to improve the patient compliance due to its chronotherapeutic action.

\section{MATERIALS AND METHODS}

Amoxicillin trihydrate was generously gifted by M/s Ranbaxy Labs. Ltd., Gurgaon, India. The polymers ethyl cellulose, HPMCK4M, K15M, K100M were obtained from M/s Colorcon Ltd., Goa, India. The sodium CMC, HEC, HPC and EudragitL-100 were obtained from M/s Evonik Ltd., Mumbai, India. Solvents like acetone, light liquid paraffin, Tween 80 were purchased from M/s Loba Chem Pvt. Ltd., Mumbai, India, while all other chemicals and reagents like sodium hydroxide, potassium dihydrogen phosphate used were of analytical grade. De-ionized double distilled water was prepared by Millipore 
filtration unit (M/s Millipore, Mumbai, India), used throughout the experimental work.

\section{Preparation of mucoadhesive microcapsules}

The microcapsules were prepared using ethyl cellulose by a solvent evaporation technique. After dissolving the ethyl cellulose (2000 $\mathrm{mg}$ ) and mucoadhesive polymer $(1000 \mathrm{mg})$ in acetone $(40 \mathrm{ml})$, amoxicillin trihydrate sodium (1000 mg) was added. The suspension was emulsified by light liquid paraffin $(350 \mathrm{ml})$ containing Tween 80 (10-12 drops). The emulsion was mechanically stirred at $500 \mathrm{rpm}$ for $2.5 \mathrm{~h}$ to remove acetone.

The microcapsules formed were collected by vacuum filtration, washed with n-hexane $(250 \mathrm{ml})$ and air dried. The formulation composition of mucoadhesive microcapsules prepared is shown in table 1 .

Table 1: Composition of preliminary mucoadhesive microspheres of amoxicillin trihydrate

\begin{tabular}{|c|c|c|c|c|c|c|c|}
\hline \multirow[t]{2}{*}{ Ingredients } & \multicolumn{7}{|c|}{ Formulation code } \\
\hline & F1 & F2 & F3 & F4 & F5 & F6 & F7 \\
\hline Amoxicillin trihydrate & $1 \mathrm{gm}$ & $1 \mathrm{gm}$ & $1 \mathrm{gm}$ & $1 \mathrm{gm}$ & $1 \mathrm{gm}$ & $1 \mathrm{gm}$ & $1 \mathrm{gm}$ \\
\hline Ethyl cellulose & $2 \mathrm{gm}$ & $2 \mathrm{gm}$ & $2 \mathrm{gm}$ & $2 \mathrm{gm}$ & $2 \mathrm{gm}$ & $2 \mathrm{gm}$ & $2 \mathrm{gm}$ \\
\hline HPMC K4M & - & $1 \mathrm{gm}$ & - & - & - & - & - \\
\hline HPMC K15M & - & - & $1 \mathrm{gm}$ & - & - & - & - \\
\hline HРMC К100M & - & - & - & $1 \mathrm{gm}$ & - & - & - \\
\hline Sodium CMC & - & - & - & - & $1 \mathrm{gm}$ & - & - \\
\hline Hydroxyethyl cellulose & - & _- & - & - & - & $1 \mathrm{gm}$ & - \\
\hline Hydroxypropyl cellulose & & & & & & & $1 \mathrm{gm}$ \\
\hline
\end{tabular}

\section{Preparation of enteric coated mucoadhesive microcapsules}

Enteric coating of mucoadhesive microcapsules was carried out by dip coating technique. The dried microcapsules were dipped into a coating solution containing Eudragit L100 (7.5\%w/v) dissolved in 100 $\mathrm{ml}$ of acetone with the help of forcep. The microspheres were air dried, and the process was repeated twice with different concentration of coating solution containing Eudragit L100 (10 \% w/v and $12.5 \% \mathrm{w} / \mathrm{v}$ ).

\section{Optimization using an experimental design}

For the systematic optimization of mucoadhesive microcapsule formulations, the experimental design methodology was employed by BBD with the help of Design-Expert software 8.0.5 (Stat-Ease Inc., MN).
The BBD was specifically selected since it requires fewer treatment combinations than other experimental designs, which involves three to four factors to optimize the formulation performance using selected responses [12]. A 3-factor, 2-level (32) BBD was employed using concentration of $\mathrm{EC}\left(\mathrm{X}_{1}\right), \mathrm{HPMCK} 100 \mathrm{M}\left(\mathrm{X}_{2}\right)$ as selected factors, while percentage drug entrapment $\left(\mathrm{Y}_{1}\right)$, percentage drug release $24 \mathrm{~h}\left(\mathrm{Y}_{2}\right)$ and percentage mucoadhesion at $6 \mathrm{~h}\left(\mathrm{Y}_{3}\right)$ were selected as obtained responses. The levels at which factors were investigated along with the obtained responses are shown in table 2. Total thirteen different formulations obtained were characterized for selected responses and analyzed for the effect of factors by response surfaces. Table 3 depicts the formulations prepared as per the experimental design along with observed responses. The optimized formulation was selected by numerical optimization.

Table 2: Independent and dependent variables for experimental design optimization

\begin{tabular}{|c|c|c|c|}
\hline \multirow[t]{2}{*}{ Independent variables (Factors) } & \multicolumn{3}{|c|}{ Range } \\
\hline & Low & & \\
\hline $\mathrm{X}_{1}=$ Concentration of EC $(\mathrm{gm})$ & 1.00 & & \\
\hline $\mathrm{X}_{2}=$ Concentration of HPMCK100 (gm) & 0.50 & & \\
\hline $\mathrm{X}_{3}=$ Concentration of Eudragit L100 $(\% \mathrm{w} / \mathrm{v})$ & 7.50 & & \\
\hline Dependent variables (Responses) & Low & High & Goal \\
\hline$Y_{1}=$ Drug entrapment $(\%)$ & 42 & 67 & Maximize \\
\hline $\mathrm{Y}_{2}=$ Drug Release $(\%)$ & 74 & 97 & Maximize \\
\hline$Y_{3}=$ Mucoadhesion $(\%)$ & 40 & 73 & Maximize \\
\hline
\end{tabular}

Table 3: Experimental runs for the formulation of mucoadhesive microcapsules as per the experimental design

\begin{tabular}{lllllll}
\hline Run & $\begin{array}{l}\text { X1 Conc. of } \\
\text { EC (gm) }\end{array}$ & $\begin{array}{l}\text { X2 Conc. of } \\
\text { HPMCK100 (gm) }\end{array}$ & $\begin{array}{l}\text { X3 Conc. of Eudragit L100 } \\
\text { (\%w/v) }\end{array}$ & $\begin{array}{l}\text { Y1 drug } \\
\text { entrapment (\%) }\end{array}$ & $\begin{array}{l}\text { Y2 drug } \\
\text { release (\%) }\end{array}$ & $\begin{array}{l}\text { Y3 mucoadhesion } \\
\text { (\%) }\end{array}$ \\
\hline 1 & 1.00 & 0.75 & 12.50 & 65 & 58 & 74 \\
2 & 1.00 & 0.75 & 7.50 & 42 & 61 & 92 \\
3 & 1.50 & 0.50 & 12.50 & 66 & 44 & 75 \\
4 & 1.50 & 0.75 & 10.00 & 57 & 60 & 86 \\
5 & 2.00 & 1.00 & 10.00 & 59 & 69 & 84 \\
6 & 2.00 & 0.75 & 7.50 & 65 & 62 & 95 \\
7 & 2.00 & 0.50 & 10.00 & 55 & 41 & 85 \\
8 & 1.50 & 1.00 & 10.00 & 46 & 72 & 96 \\
9 & 1.50 & 0.75 & 10.00 & 55 & 65 & 87 \\
10 & 1.00 & 1.00 & 12.50 & 65 & 73 & 86 \\
11 & 2.00 & 0.75 & 7.00 & 55 & 65 & 76 \\
12 & 1.50 & 0.75 & 10.00 & 44 & 64 & 87 \\
13 & 1.50 & 0.50 & 10.00 & 56 & 65 & 97 \\
14 & 1.50 & 0.75 & 12.50 & 57 & 67 & 86 \\
15 & 1.00 & 0.50 & 10.00 & 67 & 40 & 73 \\
16 & 1.50 & 1.00 & & 58 & 63 & 76 \\
\hline
\end{tabular}




\section{Characterization of uncoated microcapsules}

\section{Drug content}

Accurately weighed microcapsules, equivalent to $10 \mathrm{mg}$ of amoxicillin trihydrate sodium were crushed in a mortar-pestle, dissolved in $100 \mathrm{ml}$ of phosphate buffer $\mathrm{pH} 7.4$, mixed well and sonicated. The resultant dispersion was kept for $24 \mathrm{~h}$ for complete mixing and filtered through a Whatman filter paper. The drug content was determined spectrophotometrically using UV-Visible spectrophotometer (Shimadzu, Japan) at $273 \mathrm{~nm}$.

\section{Entrapment efficiency}

The entrapment efficiency of prepared microcapsules was determined by dissolving accurately weighed microcapsules, equivalent to $10 \mathrm{mg}$ of amoxicillin trihydrate sodium in $100 \mathrm{ml}$ of phosphate buffer $\mathrm{pH}$ 7.4. The resultant dispersion was kept for $24 \mathrm{~h}$ for complete mixing and filtered through a Whatman filter paper. The drug content was determined spectrophotometrically using UVVisible spectrophotometer (Shimadzu, Japan) at $273 \mathrm{~nm}$. The entrapment efficiency was calculated by the formula (1):

$$
\text { Entrapment efficiency }=\frac{\text { Actual drug content }}{\text { Theoritical drug content }} \times 100
$$

\section{Loose surface crystals study}

The drug encapsulated microcapsules were evaluated by loose surface crystal study to observe the excess drug present on the surface of microcapsules. Accurately weighed microcapsules, equivalent to 10 $\mathrm{mg}$ of amoxicillin trihydrate sodium were weighed, mixed with $10 \mathrm{ml}$ of phosphate buffer pH 7.4 for $5 \mathrm{~min}$, shaken and then filtered through Whatman filter paper. The amount of drug present on the surface was determined spectrophotometrically using UV-Visible spectrophotometer (Shimadzu, Japan) at $273 \mathrm{~nm}$ using regression equation $(\mathrm{Y}=0.041 \mathrm{X}-0.006)$ derived from the standard plot, and calculated as a percentage of total drug content [13].

\section{Swelling index}

The dynamic swelling property of microcapsules was determined in phosphate buffer $\mathrm{pH}$ 7.4. Accurately weighed microcapsules $(20 \mathrm{mg})$ from different formulation were placed in dissolution media (phosphate buffer pH 7.4) for $24 \mathrm{~h}$. The swollen microcapsules were collected by centrifugation at $2000 \mathrm{rpm}$ and weighed. Further, the swollen microcapsules were dried by keeping on a filter paper and the weight was noted down [14]. The percentage swelling was then calculated by the formula (2):

$$
S w=\frac{(W t W o)}{W o} \times 100
$$

Where, $\mathrm{Sw}=$ Percentage of swelling of microcapsules, $\mathrm{Wt}=$ Weight of the microcapsules at time $\mathrm{t}$ in $\mathrm{mg}$, $\mathrm{Wo}=$ Initial weight of the microcapsules in $\mathrm{mg}$

\section{Percentage moisture loss}

The drug-loaded microcapsules were evaluated for percentage moisture loss which gives an idea about its hydrophilic nature. The microcapsules weighed $20 \mathrm{mg}$ (W1) were initially kept in a desiccator containing calcium chloride at $37^{\circ} \mathrm{C}$ for $24 \mathrm{~h}$ [15]. The final weight (W2) was noted when no further change in weight of the sample was observed. The percentage moisture loss was calculated by the formula (3):

$$
\text { Percentagemoistureloss }=\frac{\left(\begin{array}{ll}
W_{1} & W_{2}
\end{array}\right)}{W_{2}} \times 100
$$

\section{Circulatory factors (Sphericity)}

The particle shape was measured by computing circulatory factor (S). The tracing obtained from the triangular microscope (Olympus ch20i, Mumbai, India) were used to calculate area (A) and perimeter (P) of the particles [13]. Finally, the circulatory factor (S) was calculated by using formula (4):

$$
S=\frac{P \times P}{12.56} A
$$

\section{Micromeritic properties of microcapsules}

Micromeritic properties of the microcapsules were determined by using the angle of repose, Carr's index and Hausner's ratio. The angle of repose was determined by the fixed funnel method. Carr's Index and Hausner's ratio were determined by tapping method. The microcapsules were tapped using USP tapped density tester (Electrolab-1020, Mumbai, India) for 1000 taps in a cylinder and the change in volume was measured[2,16]. The angle of repose, Carr's index and Hausner's ratio were calculated by formulae (5-7):

$$
\begin{gathered}
\text { Angle of repose }(\theta)=\tan ^{-\frac{h}{r}} \ldots \ldots \ldots \ldots . . . .5 \\
\text { Carr's Index }=\frac{\text { Bulk density Tapped density }}{\text { Bulk density }} \times 100 \\
\text { Hausner's ratio }=\frac{\text { Bulk density }}{\text { Tapped density }} \times 100
\end{gathered}
$$

Where, $\mathrm{h}$ and $\mathrm{r}$ are the height and radius of the powder cone in $\mathrm{cm}$, Bulk density and tapped density of the microcapsules are measured in $\mathrm{gm} / \mathrm{cm}^{3}$.

\section{Fourier transform infrared (FTIR) spectroscopy}

FT-IR spectroscopic studies were employed to characterize the possible interactions, if any, between the drug and excipients. The FTIR spectra of samples of pure drug, a physical mixture of the drug with polymers and prepared microcapsules were recorded using $\mathrm{KBr}$ disc using an FTIR spectrophotometer (Shimadzu, Japan) [17].

\section{Scanning electron microscopy (SEM)}

The shape and surface morphology of prepared microcapsules were observed by SEM (Joel Scanning Microscope JSM-5800, Japan). SEM analysis was carried out using an accelerating voltage of $20 \mathrm{kV}$ after they were gold sputtered (Jeol 4B SVG-IN, Peabody, USA).

\section{In vitro wash off test}

Modified disintegrating apparatus was used for determination of a mucoadhesive property of the prepared microcapsules by in vitro adhesion testing method, also called as a wash-off test. A freshly excised piece of goat intestinal mucosa $(5.5 \times 1.5 \mathrm{~cm})$ was mounted on a glass slide $(5.5 \times 1.5 \mathrm{~cm})$ with cotton thread. Glass slide was connected with a suitable support. About 25 microcapsules were spread on this wet rinsed tissue specimen, and immediately thereafter the support was hung onto the arm of a USP tablet disintegrating apparatus. When the disintegrating apparatus was operated, the tissue specimen was subjected a slow, regular up and down movement in the test fluid (phosphate buffer, $\mathrm{pH} 7.4$ ) at $37^{\circ} \mathrm{C}$. At specific time intervals like $0.5,1,2,3,4,5$ and $6 \mathrm{~h}$, the apparatus was stopped and a number of microcapsules adhering to mucosal tissue were counted [18, 19]. Percentage mucoadhesion was determined by formula (8):

$$
\% \text { Mucoadhesion }=\frac{\text { No. of microcapsules adhered }}{\text { Initial no. of microcapsules }} \times 100
$$

\section{In vitro drug release study}

The in vitro drug release from the mucoadhesive microcapsules were carried out using USP type II dissolution apparatus (Electrolab-TDT06L, Mumbai, India). The enteric coated microcapsules equivalent to $20 \mathrm{mg}$ of amoxicillin trihydrate sodium were filled into the hard gelatin capsule, and subjected to dissolution in $900 \mathrm{ml}$ of $0.1 \mathrm{~N} \mathrm{HCl}(\mathrm{pH} 1.2)$ for initial $2 \mathrm{~h}$ followed by phosphate buffer (pH 7.4) up to $24 \mathrm{~h}$, at $75 \mathrm{rpm}$ and $37^{\circ} \pm 5{ }^{\circ} \mathrm{C}$ temperature. Sample aliquots of $5 \mathrm{ml}$ were withdrawn periodically and replaced with $5 \mathrm{ml}$ of the fresh media. The samples withdrawn were estimated for its drug content through UV spectroscopy at $273 \mathrm{~nm}$ and percentage drug release was calculated. The dissolution tests were performed in triplicate and the drug release data were fitted to various kinetic models like zero-order, first order, Higuchi, Korsmeyer-Peppas and Baker and Lansdale model [20, 21]. The 
mean dissolution times (MDT) for $50 \%$ or $80 \%$ releases of the drug were calculated by the formula (9):

$$
M D T=\frac{\sum_{j=1}^{n} t_{j}^{\wedge} \Delta M_{j}}{\sum_{j=1}^{n} \Delta M_{j}}
$$

Where $\mathrm{j}$ is the sample number, $\mathrm{n}$ is the number of dissolution sample times, $t_{j^{\wedge}}$ is the time at the midpoint between $t_{j}$ and $t_{j-1}$ and it is easily calculated from $\frac{\mathrm{t}+\mathrm{t} j-1}{2}$ and $\Delta \mathrm{M}_{\mathrm{j}}$ is the additional amount of drug dissolved between $t_{j}$ and $t_{j-1}$

\section{Antimicrobial assay}

The antimicrobial assay of the optimized bilayer tablets was performed by using an agar plate diffusion method. The zone of inhibition (ZOI) and MIC was calculated to evaluate the efficacy of the prepared bilayer tablet formulation vis-à-vis conventional marketed preparation. The different dilutions of pure drug amoxicillin trihydrate (standard) were prepared in $\mathrm{pH} 7.4$ phosphate buffer with concentrations ranging from $1-250 \mu \mathrm{g} / \mathrm{ml}$. The prepared bilayer tablets (test) and conventional marketed immediate release tablet preparation (Amoxil ${ }^{\circledR}$, GlaxoSmithKline, India) of amoxicillin trihydrate were subjected to dissolution in $\mathrm{pH} 7.4$ phosphate buffer using the same method as mentioned earlier. The aliquots collected from dissolution study at different time intervals were filtered through $0.45 \mu \mathrm{m}$ nylon filter and carefully transferred into the wells prepared on solidified agar plate in petridish inoculated with test organisms such as Staphylococcus aureus-ATCC29213 (gram positive cocci) and E. coli-ATCC25922 (gram negative bacilli) cultured at Department of Microbiology, Shri Venkateshwara University, Gajraula. The Petri dish was kept in an incubator at a controlled temperature $\left(25{ }^{\circ} \mathrm{C}\right)$ condition. After $24 \mathrm{~h}$ incubation, the ZOI for prepared bilayer tablets and marketed preparation were measured (in $\mathrm{mm}$ ) and compared with a standard dilution of antibiotic in the concentrations of $0.5,1,2$ $3,4,6,8$ and $12 \mu \mathrm{g} / \mathrm{ml}$. On the basis of ZOIs, the MIC was calculated with respect to the amount of drug release at each specified time interval responsible to reduce the viable growth of microorganisms.

\section{Statistical analysis}

Analysis of variance (ANOVA) was performed to find out significance difference among various formulations using Prism Graph Pad software (CA, USA). Two-way ANOVA was applied on the amount of drug release at $3 \mathrm{~h}, 6$ hand $10 \mathrm{~h}$ from all formulations.

\section{Stability studies}

Accelerated stability studies were carried out for the optimized formulation as per ICH guidelines. Optimized microcapsules were packed in vials and stored at $40{ }^{\circ} \mathrm{C} / 75 \% \mathrm{RH}$ up to $6 \mathrm{mo}$ in a stability chamber. In the specified time intervals the drugs content and in vitro drug release rate was determined [23].

\section{RESULTS AND DISCUSSION}

Preparation of mucoadhesive microcapsules by experimental design

Initially, various mucoadhesive polymers were tried for preparation of microcapsules of amoxicillin trihydrate by a solvent evaporation technique. The preliminary screening showed that microcapsules prepared with mucoadhesive polymer ethyl cellulose-based HPMCK100M provides higher stability and protection to the drug and they were found to be non-aggregated (table 1). The combination of polymers in a ratio of $1: 2: 1 \mathrm{w} / \mathrm{w}$ of drug: ethylcellulose: mucoadhesive polymer (HPMCK100M) showed the formation of microcapsules satisfactorily.

Further, the microcapsules were prepared and optimized by employing BBD, at selected factors and levels. The response surface analysis was used to identify the effect of factors on the observed responses.

The optimized formulation was selected based upon the levels of factors which yielded maximum entrapment efficiency, higher sustained release profile and maximum mucoadhesion strength. The response variables considered for systematic optimization, i.e., \%drug entrapment, \% drug release in $24 \mathrm{~h}$ and \% mucoadhesion were allowed to fit in the quadratic equations with added interaction terms to correlate the studied responses with the examined factors. Statistical analysis and validation of the design was carried out by establishing mathematical relationships the form of polynomial equations for the measured responses as listed below:

Y1 (\% Drug entrapment) $=-48.05147+45.00000 \times \mathrm{X}_{1}-11.50000 \times \mathrm{X}_{2}+$ $10.75000 \times \mathrm{X}_{3}+12.00000 \times \mathrm{X}_{1} \times \mathrm{X}_{2}-4.80000 \times \mathrm{X}_{1} \times \mathrm{X}_{3}-0.40000 \times \mathrm{X}_{2} \times \mathrm{X}_{3}$

$\mathrm{Y}_{2}(\%$ Drug release in $24 \mathrm{~h})=+95.02500+29.10000 \times \mathrm{X}_{1}+2.70000 \times \mathrm{X}_{2}-$ $2.49000 \times \mathrm{X}_{3}-6.00000 \times \mathrm{X}_{1} \times \mathrm{X}_{2}-0.20000 \times \mathrm{X}_{1} \times \mathrm{X}_{3}+0.80000 \times \mathrm{X}_{2} \times \mathrm{X}_{3}$. $7.20000 \times \mathrm{X}_{1}-0.80000 \times \mathrm{X}_{2}-0.088000 \times \mathrm{X}_{3}$

$\mathrm{Y}_{3}(\%$ Mucoadhesion in $6 \mathrm{~h})=-49.27500+20.15000 \times \mathrm{X}_{1}+$ $215.80000 \times \mathrm{X}_{2}-1.51000 \times \mathrm{X}_{3}-10.00000 \times \mathrm{X}_{1} \times \mathrm{X}_{2}+1.20000 \times \mathrm{X}_{1} \times \mathrm{X}_{3}-$ $0.40000 \times \mathrm{X}_{2} \times \mathrm{X}_{3}-7.80000 \times \mathrm{X}_{1}-91.20000 \times \mathrm{X}_{2}+8.00000-003 \times \mathrm{X}_{3}$.

The quadratic polynomial equation represents the quantitative effect of variables $\left(X_{1}, X_{2}\right.$, and $\left.X_{3}\right)$ and their interactions on the responses $\left(Y_{1}, Y_{2}\right.$ and $\left.Y_{3}\right)$. The values of the coefficients $X_{1}, X_{2}$ and $\mathrm{X}_{3}$ are related to the effect of these variables on the responses $\left(\mathrm{Y}_{1}, \mathrm{Y}_{2}\right.$ and $\left.\mathrm{Y}_{3}\right)$. The positive sign represents synergistic effect, while a negative sign indicates an antagonistic effect. Fig. 1 depicts the 3D response surfaces for the selected responses in the design viz. \% drug entrapment, \%drug release in $24 \mathrm{~h}$ and $\%$ mucoadhesion.

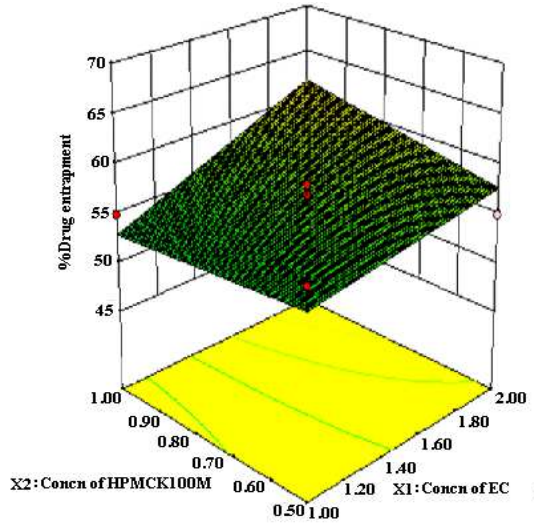

(A)

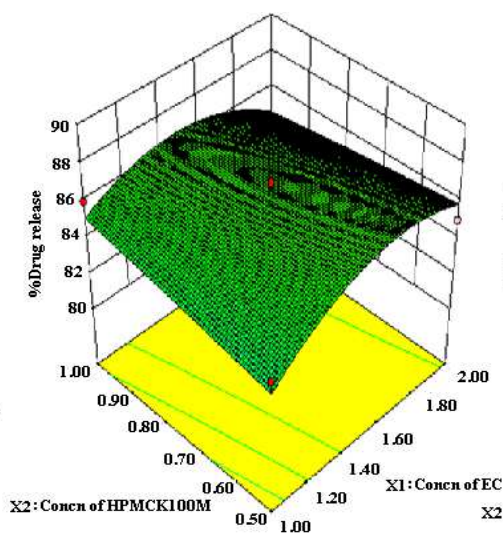

(B)

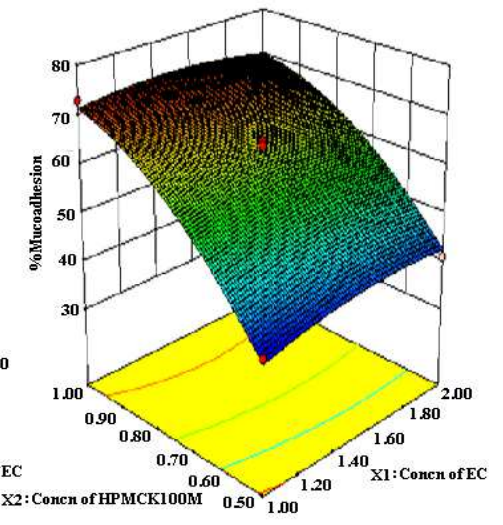

(C)

Fig. 1: 3D-Response surfaces for different dependent variables: (A) Y1 (\% drug entrapment), (B) Y2 (\% drug release) and (C) Y3 (\% mucoadhesion) as per the Box-Behnken experimental design 
Fig. 1(A) represents the effects of $X_{1}$ and $X_{2}$ and their interaction on $Y_{1}$ (\%drug entrapment) at a fixed level of $X_{3}$. The response surface showed that entrapment efficiency was gradually increased with increase in the concentration of EC $\left(\mathrm{X}_{1}\right)$, while with an increase in the concentration of HPMCK100M the entrapment efficiency was decreased. Fig. 1(B) represents the effect of $X_{1}$ and $X_{2}$ on response $Y_{2}$ (\%drug release). The response surface showed that initially drug release was increased with increase in $\left(\mathrm{X}_{1}\right)$ concentration of $\mathrm{EC}$ and at low level of HPMCK100M $\left(\mathrm{X}_{2}\right)$, however, increase the concentration of HPMCK100M (X2) at a low level of EC $\left(\mathrm{X}_{1}\right)$ revealed no significant increase in drug release. This indicated that HPMCK100M has no significant effect on drug release from microcapsules, while EC has a major role to sustain the release profile up to some extent. Fig. 1(C) indicated the effect of factor $X_{1}$ and $X_{2}$ on response Y3 $(\%$ mucoadhesion) and interaction between them. The response surface showed that $\%$ mucoadhesion was found to increase gradually with increase in the concentration of HPMCK100M $\left(\mathrm{X}_{2}\right)$, however increasing the concentration of $\mathrm{EC}\left(\mathrm{X}_{1}\right)$ has no significant effect on mucoadhesion. From the response surface analysis, it has been concluded that HPMC has a major role on mucoadhesion and $\mathrm{EC}$ has a major role on drug release, however, the Eudragit L100 has no significant role on either of the responses $\mathrm{Y} 1, \mathrm{Y} 2$ and $\mathrm{Y} 3$. Hence, it was it taken as a null factor in all the experiments and during formulation development, the triple coating procedure was employed with a fixed concentration of enteric polymer. The model was evaluated by using two way ANOVA and the ANOVA results are enlisted in table 2. Finally, the optimized formulation for preparation of mucoadhesive microcapsules was selected by numerical optimization.

Table 2: ANOVA results for various dependent variables Y1 (\% drug entrapment), Y2 (\% drug release) and Y3 (\% mucoadhesion) as per the Box-Behnken experimental design

\begin{tabular}{llll}
\hline ANOVA parameters & $\mathbf{Y}_{\mathbf{1}}$ (\% drug entrapment) & $\mathbf{Y}_{\mathbf{2}}$ (\% drug release) & $\mathbf{Y}_{\mathbf{3}}$ (\% mucoadhesion) \\
\hline SS & 756.50 & 801.29 & 1978.52 \\
df & 6 & 9 & 9 \\
MS & 126.08 & 89.03 & 219.84 \\
F-value & 9.14 & 69.63 & 45.33 \\
Prob $>$ F & 0.0014 & $<0.0001$ & $<0.0001$ \\
Std. Deviation & 3.71 & 1.13 & 2.20 \\
$\mathrm{R}^{2}$ value & 0.8458 & 0.9890 & 0.9831 \\
Suggested model & Quadratic & Quadratic & Quadratic \\
\hline
\end{tabular}

\section{Enteric coated microcapsules by dip coating technique}

The enteric coated mucoadhesive microcapsules were prepared by dip coating mainly consists of three-layer coating of Eudragit L100. The coating composition for preparing enteric coated mucoadhesive microcapsules is shown in table 3 . As a single layer and bilayer coat of enteric polymer on mucoadhesive microcapsules was unable to control the drug release in the gastric environment, therefore, trilayered coated microcapsules were prepared. The trilayered mucoadhesive microcapsules were found to protect the dosage form from the gastric acidic environment and allow the drug release in the intestinal fluid.

Table 3: Enteric coating composition for the preparation of enteric coated mucoadhesive microcapsules

\begin{tabular}{lllll}
\hline S. No. & Concentration of coating solution $(\% \mathbf{W} / \mathbf{V})$ & Enteric coating material & Solvent & Dissolution properties \\
\hline 1 & 7.5 & Eudragit L-100 & Acetone $(100 \mathrm{ml})$ & $>\mathrm{pH} 6$ \\
2 & 10 & Eudragit L-100 & Acetone $(100 \mathrm{ml})$ & $>\mathrm{pH} 6$ \\
3 & 12.5 & Eudragit L-100 & Acetone $(100 \mathrm{ml})$ & $>\mathrm{pH} 6$ \\
\hline
\end{tabular}

\section{Drug content and entrapment efficiency}

The drug content and entrapment efficiency of uncoated microcapsules were determined and shown in table 4. Drug content and entrapment efficiency were found to be in the range of $43.06 \pm 0.09$ to $70.22 \pm 0.01 \%$ and $44.87 \pm 0.19$ to $70.48 \pm 0.12 \%$ respectively. A formulation containing ethyl-cellulose with
HPMCK100M based mucoadhesive microcapsules showed maximum drug content and entrapment efficiency in comparison to other formulations. The amoxicillin trihydrate being highly soluble in water is having a tendency to diffuse out to the aqueous medium even though the sufficiently higher drug entrapment. This is due to hindered diffusion of medicament through the gel barrier formed by mucoadhesive polymer $[9,13]$.

Table 4: Characterization parameters for uncoated mucoadhesive microcapsules

\begin{tabular}{|c|c|c|c|c|c|}
\hline $\begin{array}{l}\text { Formulation } \\
\text { code }\end{array}$ & $\begin{array}{l}\text { Drug content } \\
(\%)(\text { mean } \pm S D)\end{array}$ & $\begin{array}{l}\text { Entrapment efficiency } \\
\text { (mean } \pm \text { SD) }\end{array}$ & $\begin{array}{l}\text { Loose surface crystal } \\
\text { study }(\%)(\text { mean } \pm \text { SD) }\end{array}$ & $\begin{array}{l}\text { Circulatory factors } \\
\text { (mean } \pm \text { SD) }\end{array}$ & $\begin{array}{l}\text { Moisture loss (\%) } \\
(\text { mean } \pm \text { SD) }\end{array}$ \\
\hline F1 & $43.06 \pm 0.09$ & $44.87 \pm 0.19$ & $15.09 \pm 0.05$ & $0.590 \pm 0.01$ & $33.33 \pm 0.02$ \\
\hline F2 & $65.75 \pm 0.05$ & $66.09 \pm 0.07$ & $14.14 \pm 0.04$ & $0.451 \pm 0.02$ & $11.11 \pm 0.05$ \\
\hline F3 & $58.56 \pm 0.07$ & $59.02 \pm 0.03$ & $17.61 \pm 0.07$ & $0.217 \pm 0.01$ & $11.11 \pm 0.03$ \\
\hline F4 & $70.22 \pm 0.01$ & $70.48 \pm 0.12$ & $4.71 \pm 0.07$ & $1.068 \pm 0.03$ & $12.25 \pm 0.19$ \\
\hline F5 & $55.09 \pm 0.06$ & $56.09 \pm 0.09$ & $24.56 \pm 0.13$ & $0.180 \pm 0.04$ & $25.23 \pm 0.01$ \\
\hline F6 & $48.09 \pm 0.12$ & $49.98 \pm 0.06$ & $29.35 \pm 0.04$ & $0.939 \pm 0.04$ & $5.26 \pm 0.03$ \\
\hline F7 & $46.65 \pm 0.10$ & $47.31 \pm 0.09$ & $33.99 \pm 0.32$ & $0.939 \pm 0.03$ & $17.64 \pm 0.02$ \\
\hline F8 & $42.23 \pm 0.15$ & $41.79 \pm 0.09$ & $17.17 \pm 0.54$ & $1.287 \pm 0.09$ & $32.73 \pm 0.08$ \\
\hline F9 & $45.04 \pm 0.24$ & $44.81 \pm 0.11$ & $23.44 \pm 0.78$ & $1.347 \pm 0.11$ & $22.32 \pm 0.12$ \\
\hline
\end{tabular}

Data expressed as mean $\pm \mathrm{SD}(\mathrm{n}=3)$

\section{Loose surface crystals study}

The loose surface crystal studies lend a hand to estimate the excess amount of free drug present on the surface of microcapsules in adsorbed form. The study was executed with various prepared formulations and the results were obtained (table 4 ).
The loose surface crystal was found to be in the ranges of $4.71 \pm 0.07$ to $33.99 \pm 0.32 \%$. The formulation prepared with EC and HPMCK100M showed minimum drug particles on the surface of microcapsules because HPMCK4M formed a thick viscous gel layer over the EC matrices and prevent the escape of drug crystals outside the gel barrier [13]. 


\section{Swelling index}

The swelling indexes of microcapsules prepared as per the experimental design were found to be satisfactory (table 5). Formulation F4 showed maximum swelling up to $230 \pm 0.08 \%$, whereas formulation F7 showed minimum swelling of $30 \pm 0.07 \%$, as shown in fig. 2 . The maximum swelling depends on the type of polymer used, concentration, viscosity, ionic strength as well as the presence of water. The microcapsules were undergone into swelling event due to the presence of HPMCK100M.

The swelling occurs when the polymer absorbs water and depends on the viscosity grade and ionic strength of the polymer [13, 27].

Table 5: Swelling index of uncoated mucoadhesive microcapsules

\begin{tabular}{|c|c|c|c|c|c|c|}
\hline \multirow[t]{2}{*}{ Formulation code } & \multicolumn{6}{|c|}{ Swelling index (mean \pm SD) } \\
\hline & 1h & $2 \mathrm{~h}$ & $3 \mathbf{h}$ & $4 \mathrm{~h}$ & $5 \mathrm{~h}$ & $24 \mathrm{~h}$ \\
\hline F1 & $50 \pm 0.04$ & $25 \pm 0.13$ & $30 \pm 0.04$ & $45 \pm 0.05$ & $20 \pm 0.10$ & $50 \pm 0.13$ \\
\hline F2 & $20 \pm 0.10$ & $20 \pm 0.13$ & $40 \pm 0.05$ & $64 \pm 0.07$ & $100 \pm 0.04$ & $100 \pm 0.13$ \\
\hline F3 & $10 \pm 0.13$ & $45 \pm 0.05$ & $60 \pm 0.08$ & $60 \pm 0.10$ & $80 \pm 0.08$ & $170 \pm 0.03$ \\
\hline F4 & $90 \pm 0.08$ & $125 \pm 0.03$ & $110 \pm 0.05$ & $85 \pm 0.04$ & $225 \pm 0.03$ & $230 \pm 0.08$ \\
\hline F5 & $30 \pm 0.08$ & $70 \pm 0.10$ & $45 \pm 0.04$ & $25 \pm 0.08$ & $55 \pm 0.07$ & $60 \pm 0.07$ \\
\hline F6 & $20 \pm 0.03$ & $105 \pm 0.07$ & $20 \pm 0.03$ & $60 \pm 0.10$ & $105 \pm 0.03$ & $45 \pm 0.05$ \\
\hline F7 & $15 \pm 0.07$ & $65 \pm 0.05$ & $25 \pm 0.13$ & $55 \pm 0.10$ & $30 \pm 0.04$ & $30 \pm 0.07$ \\
\hline F8 & $35 \pm 0.19$ & $53 \pm 0.18$ & $34 \pm 0.07$ & $43 \pm 0.04$ & $55 \pm 0.04$ & $65 \pm 0.16$ \\
\hline F9 & $47 \pm 0.19$ & $33 \pm 0.04$ & $25 \pm 0.11$ & $36 \pm 0.04$ & $67 \pm 0.04$ & $41 \pm 0.21$ \\
\hline
\end{tabular}

Data expressed as mean $\pm S D(n=3)$

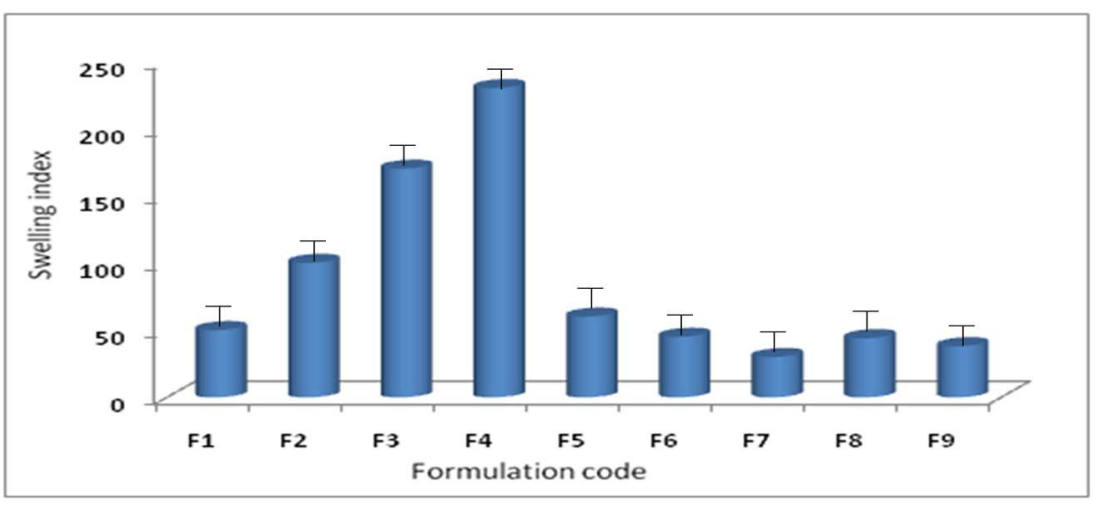

Fig. 2: Swelling index of the mucoadhesive microcapsules after 24h; Data expressed as mean \pm SD (n=3)

\section{Percentage moisture loss}

The percentage moisture loss by various mucoadhesive microcapsule formulations prepared as per experimental design are shown in table 4 . The minimum moisture loss was observed with formulation F4 and maximum moisture loss was observed with formulation F1, which ensures the presence of water content in the prepared microcapsule due to hygroscopic nature of the drug or mucoadhesive polymer. However, low proportion of water indicated proper drying and instant hardening of microcapsule upon storage [28].

\section{Circulatory factors (Sphericity)}

The circularity factor for mucoadhesive microcapsules was found to be very close to 1.00 , confirm their spherical nature as observed from the table 4. Further, the SEM was used for better understanding of the morphology of the microcapsules.

\section{Micromeritic properties}

Table 6 enlists data on the micromeritic properties of the prepared microcapsules. The average particle size of microcapsules was found to be between $46.89 \pm 0.04$ and $80.66 \pm 0.03 \mu \mathrm{m}$. The particle size depends on the amount, type or concentration of polymers used in the formulation which increases the viscosity of the solution. The tapped density was found to be between $0.312 \pm 0.02$ to $0.5 \pm 0.07$ $\mathrm{gm} / \mathrm{cm}^{3}$ and bulk density was found to be between $0.234 \pm 0.01$ to $0.468 \pm 0.03 \mathrm{gm} / \mathrm{cm}^{3}$. The Carr's Index was found in the range from $3.12 \pm 0.13$ to $16.36 \pm 0.03 \%$. The Carr's Index was found less than 17 $\%$, showed good flow property. Hausner's ratio of mucoadhesive microcapsules was found to be less than $1.33 \pm 0.03$ indicated good flow property of the prepared microcapsules. The angle of repose was found to be between $11.04 \pm 0.04$ to $43.27 \pm 0.02$ degree. From the values of angle of repose maximum data are less than $30^{\circ}$ which indicate good flow property as compared to the drug [29].

Table 6: Micromeritic properties of prepared uncoated mucoadhesive microcapsules

\begin{tabular}{|c|c|c|c|c|c|c|}
\hline $\begin{array}{l}\text { Formulation } \\
\text { code }\end{array}$ & $\begin{array}{l}\text { Average particle size } \\
(\mu \mathrm{m}) \\
(\mathrm{mean} \pm \mathrm{SD})\end{array}$ & $\begin{array}{l}\text { Tapped density } \\
\left(\mathrm{gm} / \mathrm{cm}^{3}\right) \\
(\mathrm{mean} \pm \mathrm{SD})\end{array}$ & $\begin{array}{l}\text { Bulk density } \\
\left(\mathrm{gm} / \mathrm{cm}^{3}\right) \\
(\mathrm{mean} \pm \mathrm{SD})\end{array}$ & $\begin{array}{l}\text { Angle of repose } \\
\text { (日) (mean } \pm \text { SD) }\end{array}$ & $\begin{array}{l}\text { Hausner's ratio } \\
\text { (mean } \pm \text { SD) }\end{array}$ & $\begin{array}{l}\text { Carr's index } \\
(\%) \\
(\text { mean } \pm \text { SD) }\end{array}$ \\
\hline F1 & $50.22 \pm 0.01$ & $0.312 \pm 0.02$ & $0.234 \pm 0.01$ & $43.27 \pm 0.02$ & $1.33 \pm 0.01$ & $15.00 \pm 0.01$ \\
\hline F2 & $63.33 \pm 0.13$ & $0.483 \pm 0.08$ & $0.468 \pm 0.01$ & $18.85 \pm 0.08$ & $1.03 \pm 0.03$ & $3.12 \pm 0.13$ \\
\hline F3 & $50.12 \pm 0.13$ & $0.483 \pm 0.06$ & $0.405 \pm 0.08$ & $17.52 \pm 0.07$ & $1.19 \pm 0.08$ & $16.21 \pm 0.13$ \\
\hline $\mathrm{F} 4$ & $49.33 \pm 0.04$ & $0.531 \pm 0.07$ & $0.468 \pm 0.03$ & $11.04 \pm 0.04$ & $1.06 \pm 0.01$ & $6.25 \pm 0.04$ \\
\hline F5 & $46.89 \pm 0.05$ & $0.539 \pm 0.04$ & $0.375 \pm 0.03$ & $24.94 \pm 0.08$ & $1.33 \pm 0.03$ & $16.36 \pm 0.03$ \\
\hline F6 & $80.66 \pm 0.03$ & $0.433 \pm 0.08$ & $0.382 \pm 0.09$ & $28.21 \pm 0.03$ & $1.13 \pm 0.09$ & $11.76 \pm 0.03$ \\
\hline F7 & $52.66 \pm 0.08$ & $0.365 \pm 0.03$ & $0.388 \pm 0.05$ & $29.43 \pm 0.13$ & $1.21 \pm 0.05$ & $12.99 \pm 0.08$ \\
\hline F8 & $66.01 \pm 0.10$ & $0.455 \pm 0.04$ & $0.503 \pm 0.08$ & $33.08 \pm 0.17$ & $1.67 \pm 0.06$ & $18.44 \pm 0.10$ \\
\hline F9 & $43.67 \pm 0.12$ & $0.539 \pm 0.07$ & $0.375 \pm 0.10$ & $21.35 \pm 0.09$ & $1.25 \pm 0.08$ & $10.33 \pm 0.15$ \\
\hline
\end{tabular}

Data expressed as mean $\pm \operatorname{SD}(n=3)$ 


\section{Fourier transform infrared (FTIR) spectroscopy}

The FT-IR spectra of pure drug, a physical mixture of the drug with polymers and drug-loaded microcapsule are shown in fig. 3. The peak at $3583 \mathrm{~cm}^{-1}$ indicated-NH stretching, $1157 \mathrm{~cm}^{-1}$ indicated C-O-C symmetric stretching, $10298 \mathrm{~cm}^{-1}$ for-S=0 stretching, $1384 \mathrm{~cm}^{-1}$ indicated-C-N vibrations and $1693 \mathrm{~cm}^{-1}$ for aromatic $-\mathrm{C}=\mathrm{N}$ stretching. It was observed from the spectra's of pure drug and optimized formulations that there was neither remarkable shift in the wave number of the peaks nor in the intensity of peaks proved that there was no interaction between drug and selected polymers [17].

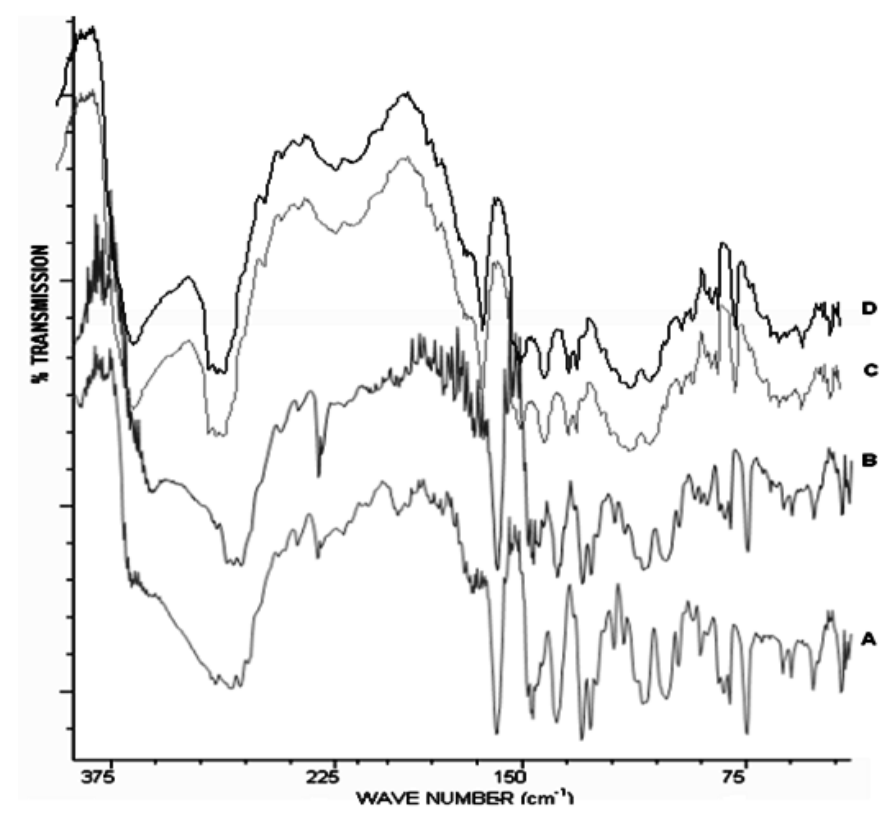

Fig. 3: FT-IR spectra of pure drug (amoxicillin trihydrate) (A); Physical mixture of pure drug+EC (B); Physical mixture of pure drug+EC+HPMCK100M (C); Optimized mucoadhesive microcapsule formulation (D)
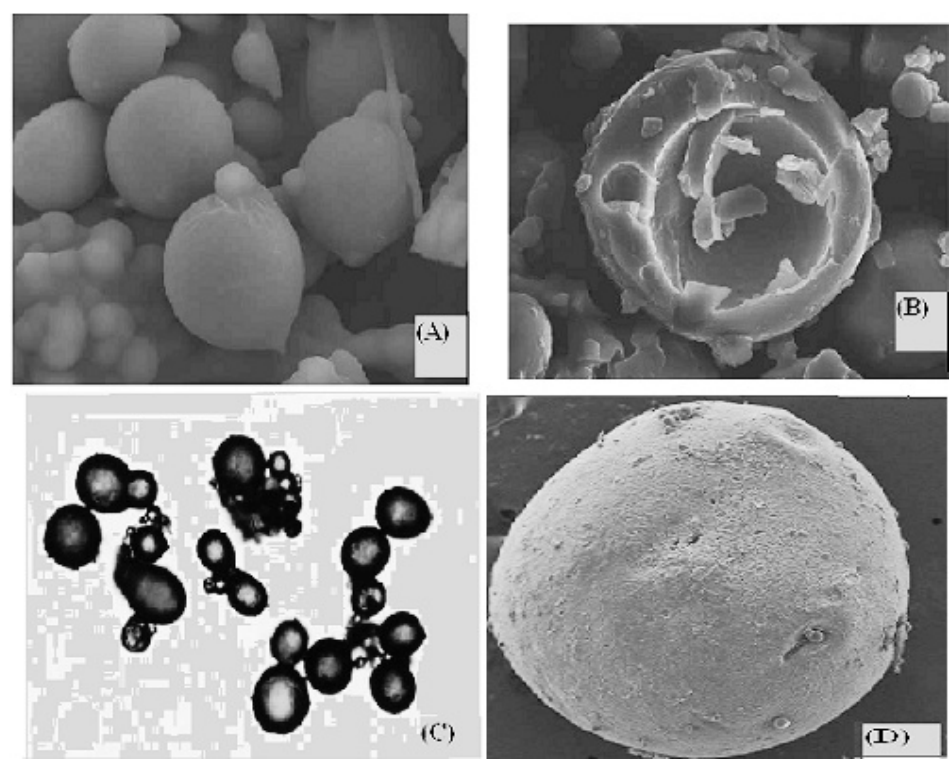

Fig. 4: SEM images of microcapsules of optimized mucoadhesive microcapsule formulation (A), broken microcapsules (B), optical microscopy images of microcapsules of optimized formulation (C) and optimized enteric coated microcapsules (D)

\section{Scanning electron microscope (SEM)}

The microcapsules were found to be discrete, non-aggregated, freeflowing and monolithic matrix type. Fig. 4 depicts the SEM photographs, which indicated that the microcapsules were spherical and completely covered with the coating polymer.

\section{In vitro wash-off test}

Fig. 5 represents the percentage mucoadhesion exhibited by different batches of prepared mucoadhesive microcapsules. In vitro wash-off test showed that prepared microcapsules exhibited fair mucoadhesive property. The wash-off was faster at intestinal $\mathrm{pH}$ medium due to critical degree of hydration, molecular weight and mobility, ionic content, solubility and viscosity of the mucoadhesive polymers. The rapid wash-off observed at intestinal $\mathrm{pH} 7.4$ is due to ionization of carboxyl and other functional groups in the polymers at this $\mathrm{pH}$, which increases their solubility and reduces bioadhesive strength (table 7). The formulations containing a higher concentration of mucoadhesive polymer (HPMCK100M) showed higher mucoadhesion property and longer wash-off time attributed due to the electrostatic attraction 
between HPMC and mucin. Also, the swelling index of the polymer affects the mucoadhesion property significantly. Higher swelling leads to the attachment of the microcapsules with mucosal surface for a longer period of time and showed slower wash-off $[17,18]$.

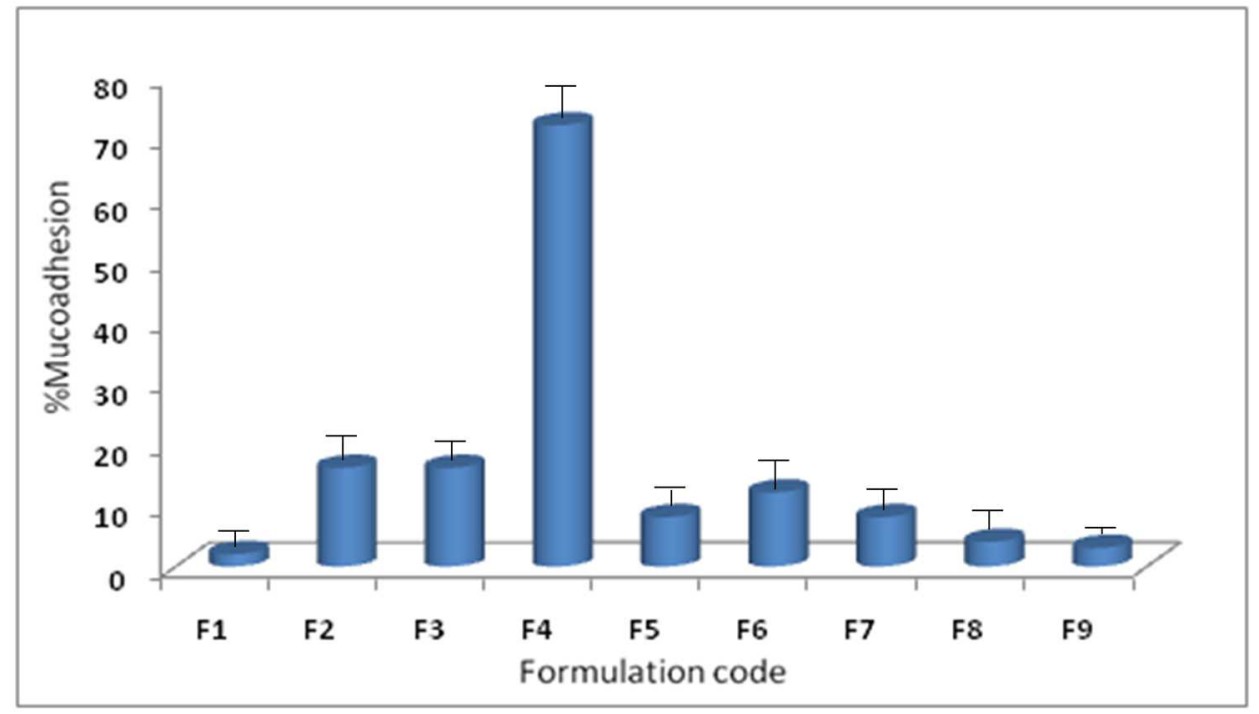

Fig. 5: \% Mucoadhesion of microcapsules of different formulations after $6 \mathrm{~h}$; data expressed as mean \pm SD (n=3)

Table 7: \% Mucoadhesion of mucoadhesive microcapsules during in vitro wash off test

\begin{tabular}{|c|c|c|c|c|c|c|c|}
\hline \multirow[t]{2}{*}{ Formulation code } & \multicolumn{7}{|c|}{$\%$ Mucoadhesion (mean \pm SD) } \\
\hline & $0.5 \mathrm{~h}$ & 1h & $2 \mathrm{~h}$ & $3 \mathbf{h}$ & $4 h$ & $5 \mathbf{5 h}$ & $6 h$ \\
\hline F1 & $12 \pm 1$ & $12 \pm 1$ & $12 \pm 1$ & $8 \pm 2$ & 0 & 0 & 0 \\
\hline F2 & $80 \pm 3$ & $64 \pm 3$ & $44 \pm 3$ & $28 \pm 1$ & $20 \pm 3$ & $20 \pm 3$ & $16 \pm 2$ \\
\hline F3 & $72 \pm 3$ & $44 \pm 3$ & $32 \pm 3$ & $28 \pm 2$ & $24 \pm 2$ & $16 \pm 2$ & $16 \pm 3$ \\
\hline F4 & $100 \pm 1$ & $100 \pm 1$ & $100 \pm 1$ & $72 \pm 1$ & $72 \pm 3$ & $72 \pm 3$ & $72 \pm 2$ \\
\hline F5 & $76 \pm 2$ & $48 \pm 1$ & $44 \pm 1$ & $40 \pm 2$ & $32 \pm 3$ & $12 \pm 2$ & $8 \pm 2$ \\
\hline F6 & $60 \pm 3$ & $48 \pm 2$ & $16 \pm 2$ & $12 \pm 1$ & $12 \pm 1$ & $12 \pm 1$ & $12 \pm 1$ \\
\hline F7 & $20 \pm 2$ & $20 \pm 3$ & $20 \pm 3$ & $16 \pm 2$ & $36 \pm 3$ & $16 \pm 1$ & $10 \pm 2$ \\
\hline F8 & $18 \pm 1$ & $23 \pm 2$ & $33 \pm 1$ & $12 \pm 3$ & $33 \pm 1$ & $25 \pm 2$ & $13 \pm 1$ \\
\hline F9 & $45 \pm 2$ & $17 \pm 3$ & $23 \pm 3$ & $10 \pm 1$ & $24 \pm 2$ & $22 \pm 3$ & $23 \pm 3$ \\
\hline
\end{tabular}

Data expressed as mean \pm SD $(n=3)$

\section{Gastric-resistance of enteric coated microcapsules}

The dissolution was carried out in the acidic medium $(0.1 \mathrm{~N} \mathrm{HCl})$ for first $2 \mathrm{~h}$ and it was found that there was no release of drug from the enteric coated microcapsules. The microcapsules remain intact during the acidic medium because the degree of ionization of carboxylic acid groups in the Eudragit L-100 increases with pH of the medium and remains intact in the acidic medium, and prevents drug release. In alkaline medium initially the enteric coating retard the drug release to some extent but as the enteric coating has no effect on drug release due to rapid dissolution of the coating layer in phosphate buffer $\mathrm{pH} 7.4$, hence the drug release depends on the viscosity of the mucoadhesive polymer present in the mucoadhesive microcapsules. Thus, enteric coated microcapsules provide good barrier property against under low $\mathrm{pH}$ conditions to prevent drug diffusion [26].

\section{In vitro drug release study}

The in vitro drug release showed that enteric-coated microcapsules provide a good barrier against drug diffusion under acidic $\mathrm{pH}$ conditions to protect the drug from degradation. The drug release was found to be sustained up to $24 \mathrm{~h}$ and depends on the concentration of HPMCK100, viscosity/molecular weight. The cumulative \% drug release from mucoadhesive microcapsules was significantly decreased with an increase in the drug-polymer ratio
(HPMCK100M) as compared to the EC. In the present study, HPMCK100M was used as a hydrophilic matrix agent because it forms a strong viscous gel on contact with aqueous media, which may be useful in the controlled delivery of highly water-soluble drugs. Faster release of the drug from the hydrophilic matrix was probably due to faster dissolution of the highly water-soluble drug from the core and its diffusion out of the matrix forming the pores for entry of solvent molecules. Incorporation of ethyl cellulose has little effect on controlling the release rate rather it helps in microencapsulation of the active pharmaceuticals [31].

Fig. 6 depicts the cumulative in vitro drug release from the enteric coated mucoadhesive microcapsule formulations prepared as per experimental design. From the in vitro drug release study the formulation F4 was considered as an optimized formulation with optimum mucoadhesion, swelling and sustaining drug release pattern. The mean dissolution data was calculated showed that formulation F4 with maximum MDT (10.17 h) and formulation F7 showed minimum MDT (3.68 h), indicated that the drug release was faster at low concentration of HPMCK100M and intermediate concentration of EC. MDT $50 \%$, the value of optimized formulation was found to be $7.05 \mathrm{~h}$. Increase in MDT value indicated that the drug release is slower, which is attributed due to increase in the thickness of barrier layers HPMC on the matrix core. 


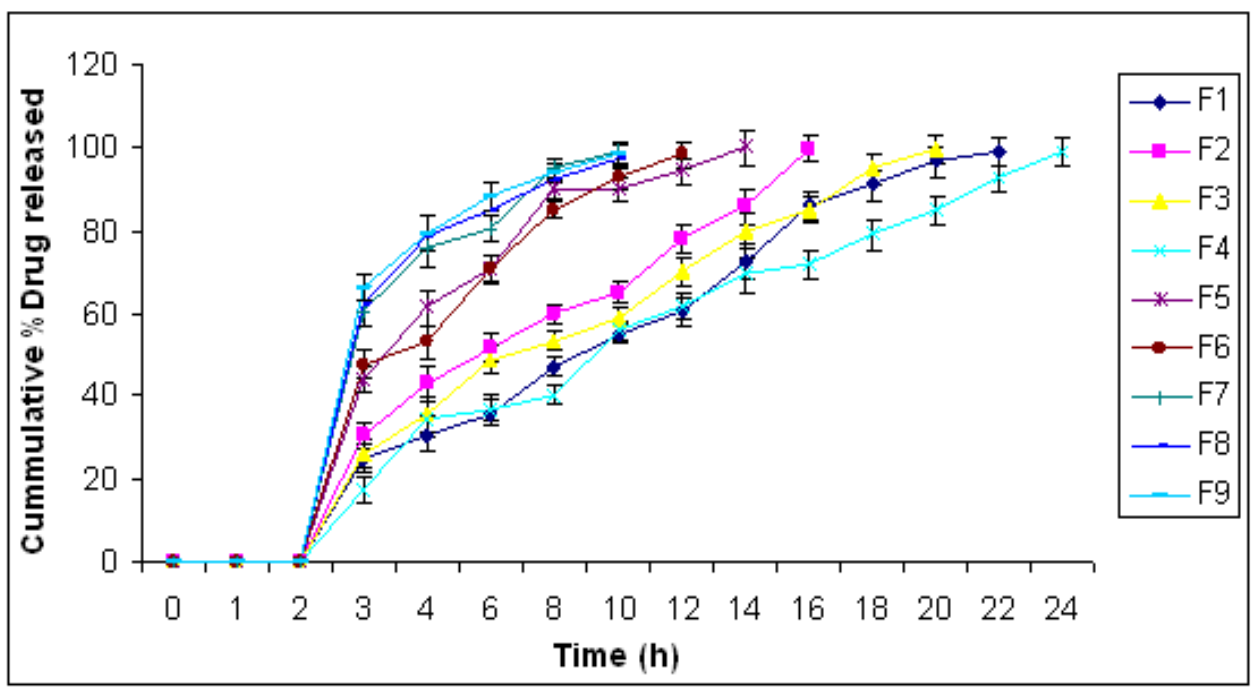

Fig. 6: Cumulative \% drug release profiles of different formulations; Data expressed as mean $\pm S D(n=3)$

Mathematical modeling of kinetic data obtained revealed that drug release from trilayer microcapsules showed non-Fickian diffusion or super case type-II (n>1.0) mechanism. The higher $\left(\mathrm{r}^{2}\right)$ value signifies that the developed layered microcapsules follow Higuchi kinetics and represents a swellable system [13, $20,31]$ (table 8).

Table 8: Various parameters of the model equations on the in vitro drug release kinetics

\begin{tabular}{|c|c|c|c|c|c|c|c|c|c|c|}
\hline \multirow[t]{2}{*}{ Formulation code } & \multicolumn{2}{|c|}{ Zero-order } & \multicolumn{2}{|c|}{ First order } & \multicolumn{2}{|c|}{ Higuchi model } & \multicolumn{2}{|c|}{ Korsmeyer-peppa's model } & \multicolumn{2}{|c|}{ Baker-lansdale model } \\
\hline & $\mathbf{r}^{2}$ & $\mathbf{K}_{\mathbf{0}}$ & $\mathbf{r}^{2}$ & $\mathbf{K}_{1}$ & $\mathbf{r}^{2}$ & $\mathbf{K}_{\mathbf{h}}$ & $\mathbf{r}^{2}$ & n & $\mathbf{r}^{2}$ & $\mathbf{K}$ \\
\hline F1 & 0.966 & -11.01 & 0.863 & 0.172 & 0.949 & -56.90 & 0.869 & 1.541 & 0.966 & 0.011 \\
\hline F2 & 0.924 & -14.48 & 0.629 & 0.274 & 0.935 & -63.37 & 0.846 & 1.767 & 0.935 & 0.145 \\
\hline F3 & 0.947 & -11.85 & 0.776 & 0.198 & 0.949 & -58.81 & 0.855 & 1.606 & 0.944 & 0.128 \\
\hline $\mathrm{F} 4$ & 0.955 & -9.58 & 0.788 & 0.138 & 0.957 & -52.37 & 0.873 & 1.481 & 0.955 & 0.096 \\
\hline F5 & 0.836 & -18.10 & 0.737 & 0.453 & 0.878 & -75.99 & 0.818 & 1.945 & 0.836 & 0.179 \\
\hline F6 & 0.884 & -21.12 & 0.944 & 0.324 & 0.878 & -79.59 & 0.829 & 2.085 & 0.884 & 0.214 \\
\hline F7 & 0.812 & -26.18 & 0.946 & 0.451 & 0.813 & -89.05 & 0.810 & 2.310 & 0.812 & 0.264 \\
\hline F8 & 0.849 & -20.04 & 0.962 & 0.433 & 0.820 & -77.51 & 0.833 & 1.876 & 0.982 & 0.187 \\
\hline F9 & 0.883 & -22.28 & 0.987 & 0.467 & 0.834 & -82.04 & 0.846 & 1.662 & 0.957 & 0.192 \\
\hline
\end{tabular}

$\mathrm{r}^{2}=$ Coefficient of correlation, $\mathrm{K}_{0}, \mathrm{~K}_{1}, \mathrm{~K}_{\mathrm{h}}, \mathrm{K}=$ Release rate constants for zero order, first order, Higuchi, Korsmeyer-Peppas and Baker-Lansdale model

\section{Antimicrobial assay}

Table 9 and 10 depicts the ZOI of standard dilutions of pure antibiotic, prepared bilayer tablets and marketed tablet formulation. It has been observed that as per the designed drug release profiles, there was a significant decrease in ZOI of the bilayer tablet formulation at $3 \mathrm{hr}$ of dissolution with value $19.3 \mathrm{~mm}$ and $22.0 \mathrm{~mm}$ for G. positive cocci and G. negative bacilli, which matched with the
ZOI of pure drug with dilution at $2 \mu \mathrm{g} / \mathrm{ml}$. On the contrary, the marketed formulation showed ZOI value of $29.3 \mathrm{~mm}$ and $29.7 \mathrm{~mm}$, which were matched with the ZOI of the pure drug with dilution at 5 $\mu \mathrm{g} / \mathrm{ml}$. This indicated that bilayer tablet formulation has lower value of MIC vis-à-vis the marketed formulation in both gram positive as well as gram negative microorganisms. Moreover, the prepared formulation indicated higher efficacy of chronomodulated release bilayer tablet formulation over the conventional marketed product.

Table 9: Antibiotic sensitivity of pure drug at standard dilution against

\begin{tabular}{lll}
\hline Conc. $(\boldsymbol{\mu g} / \mathbf{m l})$ & ZOI (in $\mathbf{m m} \pm \mathbf{S D})$ for gram positive cocci & ZOI (in mm \pm SD) for gram negative bacilli \\
\hline 0 & $0 \pm 0.00$ & $0 \pm 0.00$ \\
1 & $0 \pm 0.00$ & $0 \pm 0.00$ \\
2 & $19.1 \pm 2.5$ & $18.0 \pm 2.6$ \\
5 & $23.2 \pm 1.6$ & $22.9 \pm 2.2$ \\
10 & $28.2 \pm 2.0$ & $30.1 \pm 1.4$ \\
15 & $33.2 \pm 1.7$ & $34.8 \pm 2.0$ \\
20 & $40.5 \pm 1.4$ & $38.4 \pm 1.3$ \\
50 & $46.4 \pm 2.6$ & $43.6 \pm 2.6$ \\
100 & $51.2 \pm 1.4$ & $45.8 \pm 1.6$ \\
200 & $53.4 \pm 1.7$ & $50.2 \pm 1.7$ \\
250 & $56.3 \pm 1.9$ & $55.3 \pm 2.2$ \\
\hline
\end{tabular}

Data expressed as mean \pm SD $(n=3)$ 
Table 10: Antibiotic sensitivity of optimized mucoadhesive microcapsules and marketed formulation of amoxicillin trihydrate

\begin{tabular}{|c|c|c|c|c|}
\hline \multirow{2}{*}{$\begin{array}{l}\text { Dissolution } \\
\text { time (h) }\end{array}$} & \multicolumn{2}{|l|}{ Optimized microcapsules } & \multicolumn{2}{|l|}{ Marketed product (Amoxil) } \\
\hline & $\begin{array}{l}\mathrm{ZOI}(\text { in } \mathrm{mm} \pm \mathrm{SD} \text { ) for gram } \\
\text { positive cocci }\end{array}$ & $\begin{array}{l}\text { ZOI (in mm } \pm \text { SD) for gram } \\
\text { negative bacilli }\end{array}$ & $\begin{array}{l}\mathrm{ZOI} \text { (in } \mathrm{mm} \pm \mathrm{SD} \text { ) for gram } \\
\text { positive cocci }\end{array}$ & $\begin{array}{l}\mathrm{ZOI} \text { (in } \mathrm{mm} \pm \mathrm{SD} \text { ) for gram } \\
\text { negative bacilli }\end{array}$ \\
\hline 0 & $0 \pm 0.00$ & $0 \pm 0.00$ & $0 \pm 0.00$ & $0 \pm 0.00$ \\
\hline 0.5 & $7.6 \pm 2.07$ & $10.2 \pm 3.10$ & $12.8 \pm 2.07$ & $16.2 \pm 2.10$ \\
\hline 1 & $10.4 \pm 1.53$ & $13.3 \pm 2.33$ & $19.0 \pm 3.51$ & $21.3 \pm 1.09$ \\
\hline 2 & $12.9 \pm 3.06$ & $16.3 \pm 3.53$ & $21.7 \pm 3.06$ & $25.2 \pm 1.80$ \\
\hline 3 & $18.3 \pm 3.91$ & $21.0 \pm 1.00$ & $20.3 \pm 3.93$ & $28.7 \pm 2.90$ \\
\hline 4 & $31.2 \pm 2.02$ & $30.7 \pm 1.38$ & $30.4 . \pm 2.00$ & $36.9 \pm 1.05$ \\
\hline 5 & $35.7 \pm 2.59$ & $36.7 \pm 3.08$ & $33.7 \pm 2.92$ & $38.3 \pm 2.10$ \\
\hline 6 & $42.4 \pm 1.03$ & $39.7 \pm 4.53$ & $41.7 \pm 1.53$ & $40.1 \pm 2.01$ \\
\hline 8 & $47.1 \pm 4.01$ & $40.7 \pm 3.06$ & $44.7 \pm 2.01$ & $42.7 \pm 2.32$ \\
\hline 12 & $49.1 \pm 2.04$ & $42.0 \pm 1.03$ & $46.7 \pm 1.05$ & $44.4 \pm 1.07$ \\
\hline
\end{tabular}

Data expressed as mean $\pm \mathrm{SD}(\mathrm{n}=3)$

\section{Stability studies}

The accelerated stability studies of the optimized formulation showed that prepared microcapsules were stable for 6 mo without any change in physiochemical parameters. The drug content and dissolution rate of the formulations showed no significant change upon storage [23].

\section{CONCLUSION}

The mucoadhesive microcapsules of amoxicillin trihydrate were prepared effectively using a polymeric blend of ethyl cellulose and HPMCK100M. The gastric protection of drug release from mucoadhesive microcapsules was achieved by trilayer enteric coating with Eudragit L100 using novel dip coating technique. The physiochemical characterization of microcapsules was found to be satisfactory. The microcapsules exhibited good mucoadhesive properties under in vitro test conditions. In vitro drug release studies showed that mucoadhesive microcapsules well control drug release over an extended period of time. In vitro microbiological studies showed the superior antimicrobial effect of enteric coated mucoadhesive microcapsules on E. coli and $S$. aureus strains vis-à-vis conventional marketed formulation. Stability studies revealed that optimized microcapsules remained stable for 6 mo period of time with no change in drug content and dissolution profile.

\section{AUTHORS CONTRIBUTIONS}

The author SNP and AVG majorly responsible for planning, execution and compilation of the work, while the author AKS and HKP provided support in conducting formulation and characterization studies.

\section{CONFLICT OF INTERESTS}

We have no conflict of interest to declare

\section{REFERENCES}

1. Belgamwar VS, Gaikwad MV, Patil GB, Surana S. Pulsatile drug delivery system. Asian J Pharm 2008;2:451-63.

2. Kalantzi LE, Evangelos K, Koutris EX, Bikaris DN. Recent advances in oral pulsatile drug delivery. Recent Pat Drug Delivery Formul 2009:3:49-63.

3. Hommura Y, Sakamoto Y, Matsukawa J, Shinkawa A. Clinical study on amoxicillin in the otorhinolaryngological field. Japan J Antibiot 1975;28:353-62.

4. Stillerman M, Isenberg HD, Kacklam RR. Treatment of pharyngitis associated with a group a streptoccous: comparison of amoxicillin and potassium phenoxymethylpenicillin. J Infect Dis 1974;129:69-77.

5. Sherwood PV, Wibawa JI, Atherton JC, Jordan N, Jenkins D, Barrett DA, et al. Impact of acid secretion, gastritis, and mucus thickness on the gastric transfer of antibiotics in rats. Gut 2002;51:490-5.

6. USP 34-NF 29. Available from: http://www.usp.org/USPNF. [Last accessed on 08 Feb 2011].

7. Amoxicillin. Available from: http://en.wikipedia.org/wiki/ Amoxicillin. [Last accessed on 08 Feb 2011].
8. Beauchampa D, Labrecque G. Chronobiology and chronotoxicology of antibiotics and aminoglycosides. Adv Drug Delivery Rev 2007;59:896-903.

9. Breese BB, Disney FA, Talpey WB, Green JL. Treatment of streptococcal pharyngitis with amoxicillin. J Infect Dis 1974;129:78-80.

10. Beg S, Swain S, Gahoi S, Kohli K. Design, development and evaluation of chronomodulated drug delivery systems of amoxicillin trihydrate with enhanced antimicrobial activity. Curr Drug Delivery 2013;10:174-87.

11. Khan M, Ansari VA, Kushwaha P, Kumar A, Akhtar J. Mucoadhesive microspheres for controlled delivery of drugs. Asian J Pharm Clin Res 2015;8:17-20.

12. Helliwell M, Lim ST. The use of bioadhesives in targeted delivery. J Controlled Release 2000;16:281-90.

13. Najmuddin $M$, Shelar S, Ali A, Patel V, Khan T. Formulation and in vitro evaluation of floating microspheres of ketoprofen prepared by the emulsion solvent diffusion method. Int J Appl Pharm 2010;2:13-7.

14. Ace F, Pallotta S, Casalini S, Gabriele BP. A review of rabeprazole in the treatment of acid-related diseases. Ther Clin Risk Manag 2007;3:363-79.

15. Alli SMA, Ali SMA, Samanta A. Development and evaluation of intestinal targeted mucoadhesive microspheres of Bacillus coagulans. Drug Dev Indian Pharm 2011;37:1329-38.

16. Liu YH, Zhu X, Zhou D, Jin Y, Zhao CY, Zhang ZR, et al. pHsensitive and mucoadhesive microspheres for duodenumspecific drug delivery system. Drug Dev Ind Pharm 2011;37:868-74.

17. Sachan NK, Bhattacharya A. Basics and therapeutic potential of oral mucoadhesive microparticulate drug delivery systems. Int J Pharm Clin Res 2009;1:10-4.

18. Rowe RC, Sheskey RJ, Weller PJ. Handbook of pharmaceutical excipients. $4^{\text {th }}$ Ed. Pharmaceutical Press; 2003. p. 237-41.

19. Singh B, Kumar R, Ahuja N. Optimizing drug delivery systems using systematic "design of experiments." Part I: fundamental aspects. Crit Rev Ther Drug Carrier Syst 2005;22:27-105.

20. Singh B, Dahiya M, Saharan V, Ahuja N. Optimizing drug delivery systems using systematic "design of experiments." Part II: retrospect and prospects. Crit Rev Ther Drug Carrier Syst 2005;22:215-94.

21. Gohel MC, Amin AF. Formulation design and optimization of modified-release microspheres of diclofenac sodium. Drug Dev Ind Pharm 1999;25:247-51.

22. Chawla V, Tiwary AK, Gupta S. Characterization of polyvinylalcohol microspheres of diclofenac sodium: application of statistical design. Drug Dev Ind Pharm 2000;26:675-80.

23. Nayak BS, Ghosh SK, Tripati K, Patro B. Preparation and characterization of famotidine microcapsule employing mucoadhesive polymers in combination to enhance gastro retention for oral delivery. Int J Pharm Sci 2009;1:112-20.

24. Dandagi PM, Mastiholimath VS, Gadad AP, Iliger SR. Mucoadhesive microspheres of propranolol hydrochloride for nasal delivery. Indian J Pharm Sci 2007;69:402-7. 
25. Abu Izza K, Garcia LC, Robert D. Preparation and evaluation of zidovudine loaded sustained release microspheres optimization of multiple response variables. J Pharm Sci 1996; 85:572-4.

26. Soppimath KS, Kulkarni AR, Aminabhavi TM. Development of hollow microspheres as floating controlled release systems for cardiovascular drugs: preparation and release characteristics. Drug Dev Ind Pharm 2001;27:507-15.

27. Arya RKK, Vijay JA, Singh R. Development and evaluation of gastroresistant microspheres of pantoprazole. Int J Pharm Pharm Sci 2010;2:1575-80.

28. Muzaffar F, Murthy NV, Paul P, Semwal R, Pandy S. Formulation and evaluation of mucoadhesive microspheres of amoxicillin trihydrate by using Eudragit RS 100. Int J Chem Tech Res 2010;2:466-70.

29. Chowdary KPR, Rao YS. Design and in vitro and in vivo evaluation of mucoadhesive microcapsules of glipizide for oral controlled release: a technical note. AAPS Pharm Sci Tech 2003;4:1-6.

30. Sankalia JM, Sankalia MG, Mashru RC. Drug release and swelling kinetics of directly compressed glipizide sustainedrelease matrices: establishment of level A IVIVC. J Controlled Release 2008;129:49-58.

31. Syed IA, Narsu ML, Rao YM. In vitro release kinetics and bioavailability of oral controlled release layered matrix tablets of diltiazem hydrochloride. Int J Drug Dev Res 2011;3:234-41. 